\title{
CORNICE MODULAR WIND COLLECTOR @ FOR COLLECTION AND AMPLIFICATION OF THE VERTICAL WIND COMPONENT IN BUILDINGS FOR GENERATION OF SMALL WIND ELECTRIC ENERGY
}

\author{
J.C. Sáenz-Díez Muro ${ }^{1}$, J.M. Blanco Barrero ${ }^{1}$ E. Jiménez Macías ${ }^{1}$, J.Blanco Fernández , M. Pérez de la Parte \\ ${ }^{1}$ Department of Electrical Engineering \\ Department of Mechanical Engineering \\ E.T.S.I.I., La Rioja University \\ c/Luis de Ulloa, 20. 26004. Logroño (Spain) \\ Phone/Fax number:+0034 941 299477, e-mail: \\ juan-carlos.saenz-diez@unirioja.es \\ juan-manuel.blanco@unirioja.es \\ emilio.jimenez@unirioja.es
}

\begin{abstract}
The generation of small wind electric energy in urban spaces in general and buildings in particular has an indisputable potential for practical applications. Notwithstanding, up until now, advances in this field have been less than expected.
\end{abstract}

In order to take advantage of small wind energy, research in buildings requires the construction of a scale model for wind tunnel simulation. The difficulties regarding the construction of scale models and the availability of wind tunnels have slowed down a great deal this kind of research.

New CDF (COMPUTATIONAL FLUID DYNAMICS) software techniques have made it possible to do research in buildings for small wind energy exploitation. A virtual scale model of the building under study is developed utilizing CAD. Subsequently, the model created with CAD is inserted into the CFD software and a simulation is conducted as if in a virtual wind tunnel.

Considering the results obtained from research conducted with CFD software as well as from experimental validations in a wind tunnel, the research groups in La Rioja University known as "Modeling simulation and optimization of electrical industrial and automated fabrication systems" and "Integral Design Group " have designed an optimization system for collection of small wind energy in buildings, for electric energy production through renewable sources.

\section{Keywords}

Small Wind Energy, Urban Small Wind Energy, Renewable Electric Energy, Sustainable Buildings.

\section{Introduction}

The operating principle of the optimization system for collection of small wind energy in buildings is based in the collection of ascending wind on building facades, at their upper part (cornice), in order to make use of it to generate electric energy produced by wind energy.

The wind as it hits on buildings produces a detachment of the limit layer at the cornice which, although it causes an increase in the speed above the mentioned limit layer, it also creates big turbulences underneath it, making it difficult to collect wind energy on roofs of buildings and requiring an increase of the height at which collection takes place in order to go above the limit layer, also demanding more height as the wind generator gets placed farther from the cornice on the roof. [See Fig.1 and Fig.2].

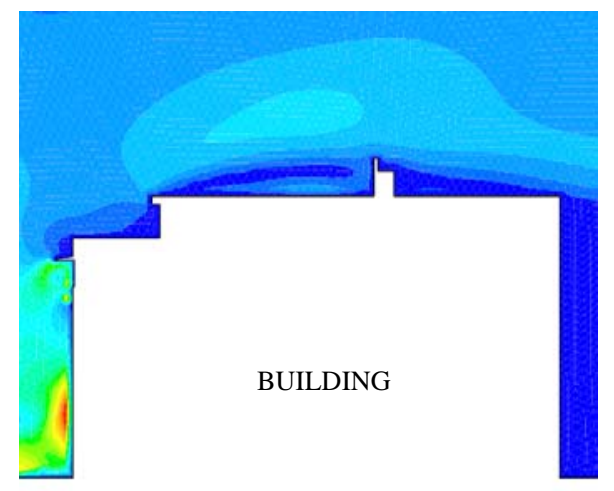

Fig.1 Contours of Velocity Magnitude (m/s) 


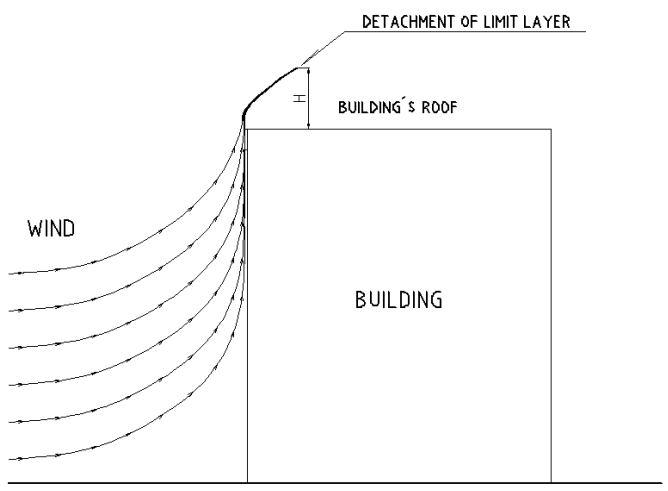

Fig.2 Detail of detachment of the limit layer

\section{Description}

The optimization system for small wind use in buildings has been called: CORNICE MODULAR WIND COLLECTOR.

Such collector is suitable for collection and use of wind's vertical component on building's facades, for generation of electrical energy from renewable wind energy sources.

It will be placed at the top of the aforesaid facades (cornice) [See Fig. 3] It does not need any tubes or devices to capture the wind on facades or roofs. It allows for collection of the wind that hitting the facades of the building ascends along them (vertical component of wind on facades), channeling it inwardly, through a series of hoods, into a pipe, usually round, which will house a wind turbinethat will transmit the mechanical energy through the correspondent coupling to the electrical generator.

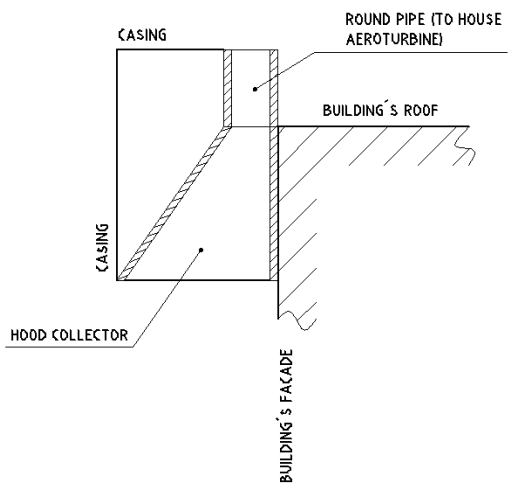

Fig.3 Placement of the cornice modular wind collector on the building.

It is important to describe the two main functions of the collector: collection of the vertical wind component and amplification of the wind speed collected.
The capture of the vertical wind component is actually much more than a component of the wind because it really is catching a big part of the incident kinetic energy in the building. The facade of the building collects the incoming wind and turns the horizontal component in vertical component. As rising up the facade the flow lines and vertical direction are joining. In the cornice the wind will be the vector sum of all flow lines incident on the facade. Therefore, this is the best place for the device placement.

The amplification of the captured wind speed is achieved by the shape of the device, similar to a bell or a funnel. By reducing the device section the speed is magnified because it must comply with the principle of conservation of mass. This property of the collector is extremely useful because it keeps the kinetic energy but with a lower step section, therefore, the wind turbines may also be smaller.

Alternatively, several pipes could be connected to one another, in such way that a single common pipe would harness the wind collected by several collectors, thus reducing the number of wind turbines. In this way, the wind's vertical component hitting the facade (a large surface) could be diverted into a narrow pipe, which amplifies the wind's speed, and allows for collection of much energy gathered at the collector with a small wind generator, resulting in a reduction of the manufacturing costs of the wind generator utilized, also influenced by the suitability of modular arrangements to almost any type of façade. Several collectors can converge into a single $\mathrm{w}$ in order to reduce the cost of installation. Individual modules can also be grouped in such way that each module will have its own wind turbine [ See Fig. 4].

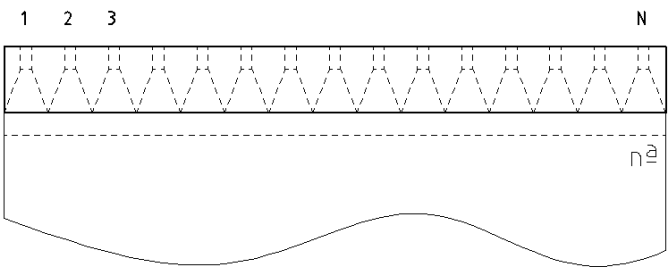

Fig.4 Grouping and distribution of the cornice modular wind collector on the facade.

The wind turbines are usually low power but it depends on the building height and its location. The turbines will be coupled to an electric generator, which will normally be of direct current (DC). With this system generators can be simply coupled in parallel. The advantage of the use of small wind turbines instead of a big one is the reduction in the size of the device profile, as the its width have to be adapted to the width of the facade. Moreover, very small wind turbines can be manufactured with very low costs. In addition, wind turbines can be standardized regardless of the building 
and location, and then the only change is the number of wind turbines installed.

\section{Simulation on CFD}

As we can see on Fig. 5, the wind's vertical component traveling up the facade, consists of all the kinetic energy of wind in the facade. The facade makes the function o an omnidirectional wind collector. Observe that the wind speed is amplified at the funnel of the cornice modular wind collector. Therefore, the wind turbine can be of reduced dimensions.

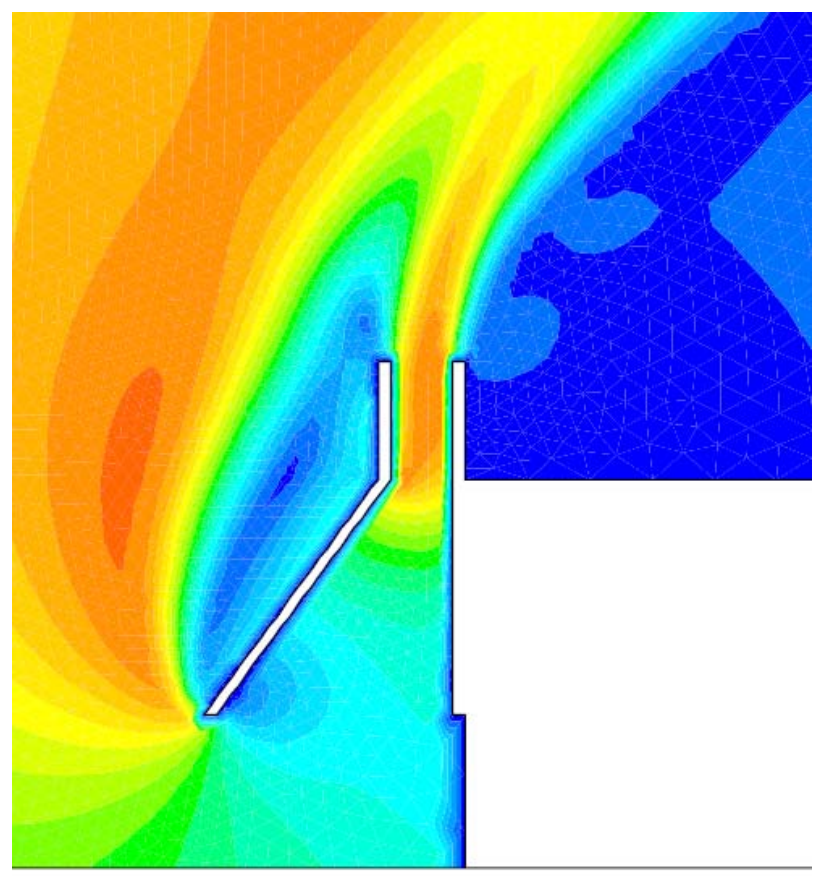

Fig. 5 Contours of Velocity Magnitude (m/s) in the cornice modular wind collector.

The wind turbine will be placed inside the tube of the top of the collector. Usually this tube will present a circular section. The type of wind turbine to install is preferably horizontal axis (although in a vertical arrangement). No need of any guidance system exists, a factor important to the variable winds mainly from the urban sites.

\section{Conclusions}

The cornice modular wind collector allows for different grouping configurations as well as different types of mini turbines. It optimizes the harnessing of wind in buildings, making it possible to increase the electric power and energy generated while reducing the size of such turbines.

As it is placed at cornices of buildings it allows the small wind generators to fit in perfectly with the building, minimizing visual impact. The guidance systems of mini-turbines can be eliminated, what reduces the noise generated and increases the power coefficient of such wind turbines.

This will facilitate the standardization of the wind turbines because the installation of the devices can be solved at any building and place by simply using the same model, adapting only the number of wind turbines to be installed.

\section{References}

[1] Sáenz-Díez, J.C.,Blanco,J.M., “Energías renovables para particulares”, I Jornadas eólicas Derrioja,pp.51-68, 2001.

[2] Suresh H.Jangamshetti,V.Guruprasada Rau, "Normalized Power Curves as a Tool for Identification of Optimum Wind Turbina Generator”, Parameters IEEE TRANSACTIONS ON ENERGY CONVERSION,VOL.16,NO.3, 2001.

[3] Blanco,J.M., Sáenz-Díez,J.C., “Sistema de captación y tratamiento de datos meteorológicos para la aplicación a la generación eléctrica proveniente de energía eólica”, XII Reunión de grupos de investigación en ingeniería eléctrica, 2002.

[4] Wilson, R.E. and Lissaman, P.B.S., "Applied Aerodynamics of Wind Power Machines”, NTIS PB 238594, Oregon State University, 1974. Sander Mertens , "Wind Energy In The Built Environment: Concentrador Effects Of Buildings Delf University of Technology”, 2007

[5] Wilson, R.E. and Lissaman, P.B.S., "Applied Aerodynamics of Wind Power Machines”, NTIS PB 238594, Oregon State University, 1974. Sander Mertens , "Wind Energy In The Built Environment: Concentrador Effects Of Buildings Delf University of Technology", 2007

[6] Andrew Grant, Cameron Johnstone, Nick Kelly, "Urban wind energy conversion: The potential of ducted turbines”, Renewable Energy, Volume 33, Issue 6, pp. 1157-1163, 2008.

[7] K.M. Lam, M.Y. H. Leung, J.G. Zhao Interference effects on wind loading of a row of closely spaced tall buildings Journal of Wind Engineering and Industrial Aerodynamics, Volume 96, Issue 5,pp.562-583 2008

[8] Nalanie Mithraratne, "Roof-top wind turbines for microgeneration in urban houses in New Zealand", Energy and Buildings, Volume 41, Issue 10, Pages 10131018, 2008.

[9] Sáenz-Díez,J.C.,Blanco,J.M.,Jiménez,E., et al., TwoDimensional Model of Wind Flow on Buildings to 
Optimize the Implementation of Mini Wind Turbines in Urban Spaces, International Conference on Renewable Energies and Power Quality (ICREPQ'10), 2010.

[10] Sáenz-Díez,J.C.,Blanco,J.M.,Jiménez,E., et al., Solicitud de Patente ES2346176A1 “Colector eólico modular de cornisa”. 
